\title{
JOGO EMPRESARIAL NA PERSPECTIVA DO ENSINO- APRENDIZAGEM: APLICAÇÃO DO BEER GAME
}

\author{
Marianna Cruz Campos Pontarolo-marianna.campos@ufersa.edu.br \\ Universidade Federal Rural do Semi-árido / UFERSA, DENGE \\ Rua Gamaliel Martins Bezerra, s/n \\ 59515-000 - Angicos - RN
}

Rayane Cabralda Silva - rayane_cabral@hotmail.com

Universidade Federal Rural do Semi-árido / UFERSA, DENGE

Rua Gamaliel Martins Bezerra, $s / n$

59515-000 - Angicos - RN

Letícia Soares Teixeira de Souza - lstssouza@hotmail.com Universidade Federal Rural do Semi-árido / UFERSA, DENGE Rua Gamaliel Martins Bezerra, s/n

59515-000 - Angicos - RN

Christiane Lopes dos Santos - christiane.lopes18@gmail.com Universidade Federal Rural do Semi-árido / UFERSA, DENGE Rua Gamaliel Martins Bezerra, $s / n$

59515-000 - Angicos - RN

Rosineide Luzia Avelino da Silva - rosineideavelino20@gmail.com Universidade Federal Rural do Semi-árido / UFERSA, DENGE Rua Gamaliel Martins Bezerra, $s / n$ 59515-000 - Angicos - RN

Resumo: Os jogos empresariais são utilizados no ensino com o objetivo de simular um ambiente de negócios, sendo capazes de relacionar os conceitos de uma aula teórica com um problema real em uma situação controlada. Nesse sentido, o presente estudo tem como objetivo analisar a capacidade técnica em termos de tomada de decisão, trabalho em grupo e domínio de conceitos dos discentes quanto ao gerenciamento da cadeia de suprimentos, por meio da aplicação do Beer Game como elemento avaliativo dentro de uma disciplina e em eventos, como uma oficina. Observou-se que essa prática dentro do planejamento da disciplina é um meio para consolidar, de forma dinâmica e centrada no aluno, o que foi aprendido. E em eventos, possibilita expor ao aluno o impacto da tomada de decisão não apenas em sua empresa, mas em toda a cadeia. Para mais de 61,54\% dos participantes, o jogo reflete totalmente ou quase totalmente uma situação real de tomada de decisão, com resolução de problemas, raciocínio lógico, senso crítico, trabalho em equipe, integra-se com outras disciplinas e permite o aprendizado de conceitos importantes como "cadeia de suprimentos", "efeito chicote" e "logística".

Palavras-chave: Jogos empresariais. Beer Game. Logística. Cadeia de Suprimentos. 


\section{INTRODUÇÃO}

Os profissionais da área de educação superior buscam formar profissionais que atuem no mercado de trabalho com autonomia e competência. O principal desafio dos docentes é descobrir um método para que o aluno transcenda a natureza de espectador e seja ativo no processo ensino-aprendizagem. Dessa forma, a promoção da aprendizagem exige uma metodologia de ensino capaz de tornar o aluno protagonista deste processo, desenvolvendo a criticidade sobre os conteúdos ministrados, bem como relacionar o conhecimento com situações reais. Mediante esta necessidade, as Metodologias Ativas de Ensino têm conquistado espaço nas salas de aula das universidades (PINTO et. al, 2012).

Fonseca e Mattar Neto (2017) compreendem Metodologias Ativas como estratégias didáticas focadas na aprendizagem ativa do aluno, onde o docente conduz a formação do pensamento crítico acerca de um problema essencial à sua formação, que desperta a curiosidade e estimula a tomada de decisão individual ou coletiva. Para Mitre (2008), as Metodologias Ativas motivam o discente a refletir e examinar os problemas de forma multidisciplinar, favorecendo resoluções assertivas e embasadas. Neste contexto, emergem os jogos empresariais como uma ferramenta de ensino-aprendizagem. Esses tipos de jogos permitem que os docentes simulem situações reais de um ambiente de negócios, com o intuito de unir os conceitos da aula teórica com um problema simulado em um ambiente controlado (SILVA, 2013).

O jogo empresarial foco desta pesquisa é o Beer Game. Este jogo foi desenvolvido pelo Massachusetts Institute of technology (MIT) e simula uma cadeia de suprimentos de cerveja. Os participantes gerenciam os estoques e cabe a cada elo o pedido realizado ao seu fornecedor. O gerenciamento da cadeia de suprimentos é um conteúdo denso e com a aplicação deste jogo é possível demonstrar, de forma prática, as dificuldades de gerenciar uma cadeia descentralizada e expor as consequências desse tipo de gestão (SILVA, 2013).

O presente trabalho tem como objetivo analisar a capacidade técnica (tomada de decisão, trabalho em grupo e o domínio dos conceitos) dos discentes em relação ao gerenciamento da cadeia de suprimentos, conteúdo da disciplina de Logística e Gestão de Rede de Suprimentos I no curso de engenharia de produção da UFERSA - Campus Angicos, por meio da aplicação do Beer Game. Comparando esta aplicação a uma oficina realizada em um evento.

Assim, esse trabalho divide-se em cinco partes. Além da introdução, que apresenta a contextualização do tema, objetivos e justificativa da pesquisa; o referencial teórico expõe os principais conceitos da temática abordada; características e funcionamento do jogo; seguido da aplicação, avaliação e discussão dos resultados; avaliação do jogo pelos participantes e considerações finais.

\section{JOGOS NA PERSPECTIVA DE ENSINO E APRENDIZAGEM E O BEER GAME}

Nos tempos atuais é visível a transição ocorrida na educação devido ao avanço de métodos e tecnologias que impulsionam o aluno a não se limitar apenas às salas de aula, mas a explorar ambientes físicos e virtuais que aprimorem o seu aprendizado. Neste caso, com o objetivo de facilitar a compreensão dos conteúdos a serem trabalhados, o setor pedagógico percebe a importância de se incrementar os jogos no dia-a-dia no processo ensino aprendizagem. Além disso, os jogos têm se tornado uma ferramenta que auxilia os docentes a resolverem problemas atuais, como: evasão escolar, dificuldade de aprendizado, falta de disciplina e motivação dos alunos, possibilitando aos professores uma forma melhor de dinamizar o seu trabalho (RIBEIRO; RBEIRO; LEÃO JUNIOR, 2012). 
No ensino superior, a exemplo do curso de Engenharia de Produção, a utilização de jogos também se alinha ao objetivo de facilitar o processo de obtenção do conhecimento. Neste caso, destacam-se jogos voltados à área de produção, que por meio de simulações facilitam a metodologia de ensino, como: Jogo de Fábrica de Canetas (PONTAROLO et al., 2019a) focado nos conceitos de produção puxada e empurrada; o Jogo de Conceitos (PONTAROLO et al., 2019b) focado nos modais da transportes e também em sistemas de informação, e o Beer Game (STROZZI, BOSCH e ZALDÍVAR, 2006).

De acordo com Strozzi, Bosch e Zaldívar (2006), o Beer Game foi criado em 1960 pela Sloan School of Management com o intuito de instruir conceitos de gestão da cadeia de suprimentos. Seu objetivo é minimizar os custos logísticos (estoque e transporte) por meio de simulações, e simultaneamente, atender aos requisitos do cliente. O jogo representa uma cadeia de suprimentos em quatro níveis: o Varejista, o Atacadista, o Distribuidor e, por fim, a Fábrica. As ordens de pedido começam pelo cliente consumidor que solicita o produto ao varejista, esse, por sua vez, realiza o pedido ao atacadista, que solicita ao distribuidor e esse realiza o pedido a fábrica, que, diferentemente, realiza os pedidos a si mesmo.

Alguns detalhes são importantes: a entrega dos produtos de um nível para outro, portanto, para o pedido chegar até o varejista vindo da fábrica, há um atraso de 3 semanas; além disto, os pedidos feitos não poderão ser cancelados e não há devolução do excedente. Toda semana uma nova solicitação do consumidor é feita ao varejista e este deve avaliar os custos cumulativos do estoque, e, acima de tudo, satisfazer o cliente de modo a não o deixar esperando pelo produto.

O objetivo final do Beer Game é alcançar o menor custo da cadeia, esse fato estimula a cooperação entre os membros da cadeia de suprimentos, a elaboração de estratégias para minimização dos custos e exprime a importância da informação. Ao logo do jogo vários conceitos são abordados, como por exemplo: logística, lead time, backorder, custos, cadeia de suprimentos, estoque de segurança e efeito chicote (SILVA, 2013).

\section{CARACTERÍSTICAS E FUNCIONAMENTO DO BEER GAME - EP/ANGICOS}

O Beer Game - EP/ANGICOS (BG) tem o objetivo de simular uma cadeia de suprimentos de cerveja com 4 membros envolvidos: fábrica, distribuidor, atacadista e varejista. Cada um desses participantes deve fazer pedidos semanais que devem variam entre 1 palete e no máximo 40 paletes para atender a demanda do consumidor final.

$\mathrm{O}$ jogo é composto por duas simulações. A primeira inclui a rodada $0+12$ rodadas (semanas) e a segunda parte se inicia logo ao final das discussões da primeira parte. Cada cadeia deve ter 4 participantes obrigatoriamente. Além disso, fazem parte da aplicação: o mediador, que fará a condução do jogo e o líder que acompanhará as ações desenvolvidas especificamente na sua cadeia. Totalizando, 1 mediador e 4 líderes. A equipe aplicadora faz toda a preparação da sala conforme a Figura 1. 


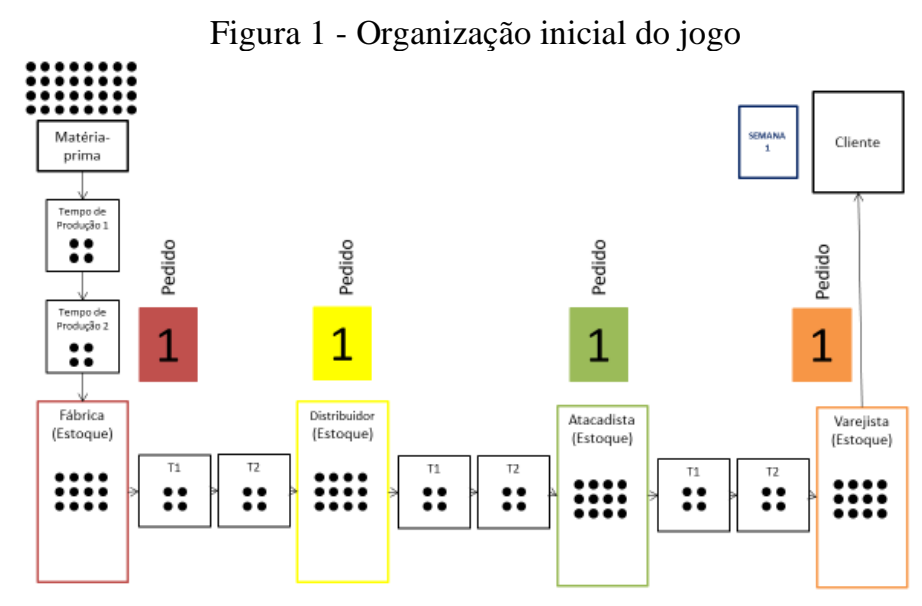

Fonte: Dados da pesquisa (2020)

\subsection{Simulação 1}

Com os 4 participantes por equipe já dispostos, cada um deverá assumir uma atribuição do sistema (fábrica, distribuidor, varejista, atacadista). Inicia-se uma apresentação sobre o jogo, mostrando os custos e simulando o passo a passo de cada participante. A semana 0 é a semana teste. A demanda do cliente e os pedidos devem ser iguais a 4 (para os participantes treinarem a dinâmica do jogo). Não pode haver comunicação e cada estoque deve ficar coberto por uma proteção (neste caso foram potes de sorvete com uma abertura frontal).

Após a semana teste, o jogo começará de fato a partir da primeira realização de pedido, ao fim da rodada 0 . As rodadas que seguem da $1^{\mathrm{a}}$ até a $12^{\mathrm{a}}$ seguem o mesmo padrão. As demandas do consumidor já deverão estar prontas. É sugerida a seguinte sequência: 12, 12, 12, 5, 5, 8, 5, 3, 3, 3, 5, 8 (a demanda pode variar de acordo com o aplicador). Ao fim dessa primeira simulação, serão mostrados os resultados obtidos pela planilha, gráficos e a equipe vencedora. Aqui, deverá ser gerada uma discussão sobre as estratégias utilizadas ou não utilizadas, o que deu certo, o que deu errado e o porquê dos participantes acharem que deu aquele resultado. Nesse momento, deverão ser feitas perguntas relacionadas aos conceitos abordados do jogo.

\subsection{Simulação 2}

Nesta segunda etapa, novas regras serão disponibilizadas, com o objetivo de facilitar discussões e melhor entendimento da cadeia de suprimentos. Serão retiradas inicialmente as proteções de todos os estoques e serão dados 2 minutos para que as equipes decidam qual estratégia usarão e como se planejarão melhor (na rodada 0 e após algumas rodadas).

Entre as rodadas 1 e 12 são realizados os mesmos procedimentos da Simulação 1, exceto a carta de demanda do cliente que agora é virada pelo próprio líder e ficando à vista. A cada 3 semanas, cada equipe poderá se reunir durante 2 minutos para discutir (serão 3 intervalos). A demanda sugerida para o cliente segue a sequência de $8,12,8,5,5,12,8,5,5,3,5,8$. Ao final do jogo, são expostos os gráficos e o resultado final do jogo (Custo total da rodada $1+$ Custo total da rodada 2), explicitando os conceitos envolvidos, principalmente o efeito chicote.

\subsection{Controle e Análise do jogo}

O controle e análise do jogo são feitos por meio de uma planilha. A partir da alimentação da planilha com os pedidos feitos, são gerados gráficos, os custos por cadeia, custos por participante e seus respectivos desempenhos. A equipe vencedora será aquela que apresentar os menores custos, sendo através do atendimento integral das demandas ou do melhor controle de 
seus estoques. Tendo em vista que, cada palete atrasado tem um custo semanal de $\mathrm{R} \$ 1,00 \mathrm{e}$ cada palete em estoque ou em transporte tem um custo semanal de $\mathrm{R} \$ 0,50$.

\section{APLICAÇÃO, AVALIAÇÃO E DISCUSSÃO DOS RESULTADOS}

Neste tópico serão avaliadas as aplicações de três situações: duas com alunos que cursaram a disciplina de Logística e Gestão de Redes de Suprimentos I, nos semestres letivos 2018.2 e 2019.2, e, uma aplicação no Workshop de Engenharia de Produção (WEP) no ano de 2019, onde participaram alunos de outros cursos, como Bacharelado em Ciência e Tecnologia (BCT), Licenciatura em Computação e Informática (LCI) e Engenharia Civil (EC).

A dinâmica já é inclusa desde o primeiro momento no planejamento da disciplina, com isso, uma pontuação é atribuída na referida unidade avaliativa. Os alunos são previamente avisados sobre a data de aplicação do jogo. As aplicações têm duração aproximada de 3 horas, sendo ministradas pela docente e discente monitora da disciplina (mediadora), com o apoio de mais 4 alunos que já participaram do BG como líderes de cada uma das cadeias (Tabela 1).

Tabela 1 - Quantidade de participantes do Beer Game

\begin{tabular}{cccc}
\hline \multicolumn{4}{c}{ Semestre letivo de aplicação } \\
\hline & $\mathbf{2 0 1 8 . 2}$ & $\mathbf{2 0 1 9 . 2}$ & $\mathbf{2 0 1 9}($ WEP) \\
\hline $\mathbf{N}^{\mathbf{0}}$ de participantes & 8 & 16 & 16 \\
$\mathbf{N}^{\mathbf{0}}$ de cadeias de suprimentos & 2 & 4 & 4 \\
\hline
\end{tabular}

Fonte: Dados da pesquisa (2020)

Baseado nas respostas dos 40 participantes e na desenvoltura das 10 equipes, posteriormente serão apresentadas as opiniões dos alunos sobre a dinâmica e os resultados das respectivas equipes.

\subsection{Custos totais}

No BG, o objetivo de cada cadeia é minimizar o seu custo total. Para que isso aconteça, é preciso entender o comportamento e a necessidade de cada cliente, pois muitas vezes a demanda prevista não se iguala a demanda real, causando o efeito chicote. Esse efeito corresponde a discrepância entre a demanda real e a demanda prevista, o que pode causar o acúmulo de produtos no estoque ou a falta destes, tendo seu efeito refletido ao longo de toda cadeia. Deste modo, é muito importante que todas as operações logísticas estejam alinhadas por toda cadeia, o que inclui a troca de informações, a fim de minimizar as consequências desse efeito. $\mathrm{Na}$ Tabela 2 são apresentados os custos totais das equipes participantes nas duas simulações.

Tabela 2 - Custos totais das equipes participantes do Beer Game

\begin{tabular}{|c|c|c|c|c|c|c|}
\hline & & $\begin{array}{c}\text { Custo total (R\$) } \\
\text { Simulação } 1 \\
\end{array}$ & $\begin{array}{c}\text { Custo total (R\$) } \\
\text { Simulação } 2 \\
\end{array}$ & $\begin{array}{c}\text { Custo } \\
\text { total }\end{array}$ & $\begin{array}{c}\text { Diferença em } \\
\text { custos }(R \$)\end{array}$ & $\begin{array}{l}\text { Diferença } \\
\text { percentual }\end{array}$ \\
\hline \multirow{2}{*}{$\begin{array}{c}\text { LOG } \\
2018.2\end{array}$} & 1 & $1.343,50$ & 410,5 & 1.754 & -933 & $-69 \%$ \\
\hline & 2 & 867 & 408,5 & $1.275,5$ & $-458,5$ & $-53 \%$ \\
\hline \multirow{4}{*}{$\begin{array}{c}\text { LOG } \\
2019.2\end{array}$} & 1 & 1.380 & 576,5 & $1.956,5$ & $-803,5$ & $-58 \%$ \\
\hline & 2 & 684 & 394 & 1.078 & -290 & $-42 \%$ \\
\hline & 3 & 962 & 364,5 & $1.326,5$ & $-597,5$ & $-62 \%$ \\
\hline & 4 & 460,5 & 407 & 867,5 & $-53,5$ & $-12 \%$ \\
\hline \multirow{4}{*}{$\begin{array}{l}\text { WEP- } \\
2019\end{array}$} & 1 & 530,5 & 571,5 & 1.102 & 41 & $8 \%$ \\
\hline & 2 & 577 & 548 & 1.125 & -29 & $-5 \%$ \\
\hline & 3 & 559 & 462 & 1.021 & -97 & $-17 \%$ \\
\hline & 4 & 659,5 & 446,5 & 1.106 & -213 & $-32 \%$ \\
\hline
\end{tabular}

Fonte: Dados da pesquisa (2020). 
Em análise a Tabela 2, é perceptível a diferença nos custos entre as duas simulações, onde a primeira detém os custos mais elevados, assim, todas as equipes atenderam o objetivo de minimizar os custos (exceto a Equipe 1 do WEP-2019). Diante disso, é válido salientar que as equipes vencedoras foram as que obtiveram o menor custo total, somadas as duas simulações.

Os valores resultantes podem ser justificados pela falta de informação que os membros tinham, dificultando o alinhamento das operações logísticas da cadeia. É notória a diferença dos custos em todas as cadeias (exceto uma). Isso ocorre, em razão da troca de informações que passa a existir na segunda simulação, permitindo que os participantes das cadeias de suprimento alinhem suas operações logísticas, reduzindo cada vez mais as consequências do efeito chicote.

\subsection{Avaliação dos pedidos}

É importante conhecer o comportamento de cada cadeia, bem como a quantidade de pedidos realizados por cada equipe, para melhor entendimento desse fenômeno. Neste caso, foi utilizado o gráfico da Equipe 1 na Simulação 1 no semestre 2018.2, para melhor exemplificar o efeito, como visto na Figura 2.

Figura 2 - Gráficos de pedidos da Equipe 1 na Simulação 1, semestre 2018.2

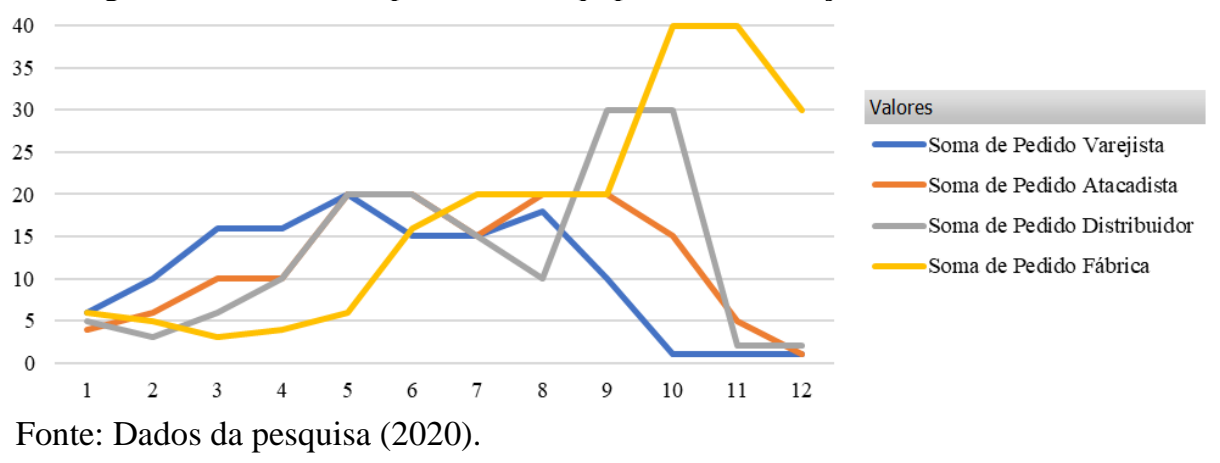

Ao analisar o gráfico, é perceptível que os pedidos variam da quantidade mínima à máxima, propostas pelas regras do jogo. Mesmo com essa oscilação no número de pedidos, em alguns momentos os pedidos se mantem aproximados, iguais em alguns pontos ou até mesmo estáveis. Comportamento esse que seria ideal, se assumido por todos os membros da cadeia, comprovando que as operações logísticas estão alinhadas, ainda que nesse tipo de simulação a não permissão para troca de informações dificulte esse processo. Na Figura 3 é apresentado o gráfico da Equipe 4 do WEP-2019, utilizado para mostrar a Simulação 2.

Figura 3 - Gráficos de pedidos da Equipe 4 na Simulação 2, WEP-2019

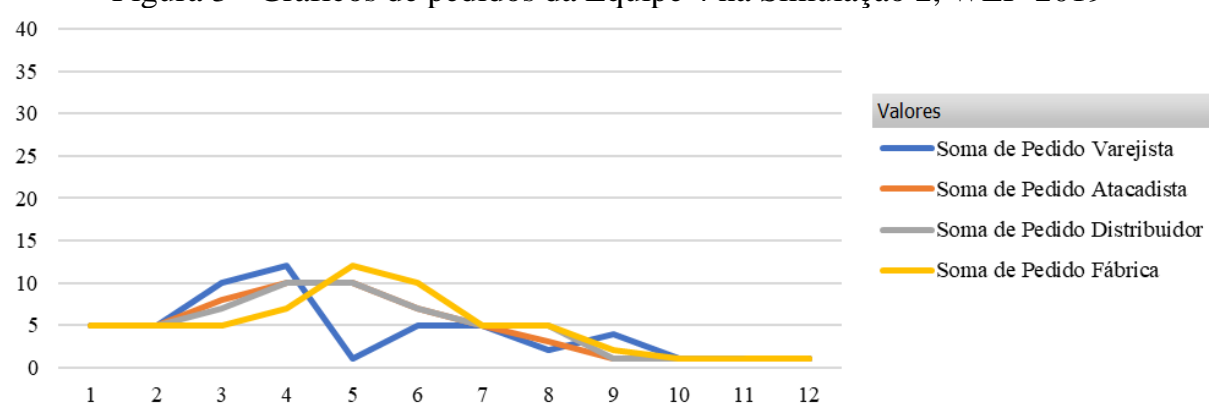

Fonte: Dados da pesquisa (2020).

Ao contrário dos números de pedidos realizados pela equipe que foi exemplo da Simulação 1, que variavam da quantidade mínima à máxima, essa equipe não realizou o pedido máximo 
em nenhum momento. Mesmo assim, é perceptível que as linhas se aproximaram e mantiveramse estáveis, dentro de um intervalo padrão visível nos gráficos, em alguns momentos. Isso aponta para o alinhamento das operações logísticas, facilitado pelas regras do jogo nessa simulação, já supracitadas nesse artigo. Na Tabela 3 é apresentada a comparação entre os pedidos nas duas simulações das duas cadeias com melhores e piores resultados.

Tabela 3 - Comparação dos pedidos médios nas Simulações 1 e 2

\begin{tabular}{cccccccc}
\hline Simulação 1 - Pedido Médio & & Custo total (R\$) & Fábrica & Distribuidor & Atacadista & Varejista \\
\hline \multirow{2}{*}{ LOG 2019.2 } & $\mathbf{1}$ & 1.380 & 12,67 & 13,67 & 11,42 & 10,75 \\
& $\mathbf{4}$ & 460,5 & 4,25 & 4,58 & 5,75 & 4,42 \\
\multirow{2}{*}{ WEP-2019 } & $\mathbf{1}$ & 530,5 & 6,58 & 8,67 & 7,67 & 7,17 \\
& $\mathbf{4}$ & 659,5 & 11,42 & 9,17 & 9,67 & 5,83 \\
\hline Simulação 2 - Pedido Médio & & Custo total (R\$) & Fábrica & Distribuidor & Atacadista & Varejista \\
\hline \multirow{2}{*}{ LOG 2019.2 } & $\mathbf{1}$ & 576,5 & 7,5 & 8,7 & 7,5 & 5,9 \\
& $\mathbf{3}$ & 364,5 & 3,8 & 4,9 & 5,5 & 5,8 \\
\multirow{2}{*}{ WEP-2019 } & $\mathbf{1}$ & 571,5 & 6,8 & 7,5 & 4,8 & 4,6 \\
& $\mathbf{4}$ & 446,5 & 4,9 & 4,8 & 4,8 & 4,3 \\
\hline
\end{tabular}

Fonte: Dados da pesquisa (2020)

Assumindo que os valores sejam a média dos pedidos de cada participante, é possível analisar que as equipes que obtiveram o menor custo total foram aquelas com pedidos médios também menores, o que acontece de forma inversa para as equipes com maiores custos totais.

\subsection{Avaliação do estoque e backorder}

Estoque e backorder são conceitos vistos na dinâmica que estão interligados, visto que backorder é a classificação dada aos pedidos que estão pendentes, ou seja, que ainda não foram atendidos. Isso acontece quando o número de produtos em estoque não é capaz de suprir a demanda do cliente. Na Tabela 4 são apresentados os custos totais de cada equipe analisada, bem como o estoque e backorder médio para cada membro da cadeia.

Tabela 4 - Comparação do estoque e backorder médios nas Simulações 1 e 2

\begin{tabular}{|c|c|c|c|c|c|c|c|c|c|c|}
\hline \multicolumn{11}{|c|}{ Simulação 1} \\
\hline & & & \multicolumn{4}{|c|}{ Estoque médio } & \multicolumn{4}{|c|}{ Backorder médio } \\
\hline \multicolumn{3}{|c|}{ Custo total (R\$) } & $\mathbf{F}$ & D & $\mathbf{A}$ & $\mathbf{V}$ & $\mathbf{F}$ & D & $\mathbf{A}$ & $\mathbf{V}$ \\
\hline \multirow{2}{*}{ LOG 2019.2} & 1 & 1.380 & 6,5 & 4,6 & 3,2 & 1,0 & 1,8 & 30,2 & 41,6 & 1,9 \\
\hline & 4 & 460,5 & 6,4 & 12,6 & 10,8 & 0,3 & 0,0 & 0,0 & 0,0 & 8,6 \\
\hline \multirow{2}{*}{ WEP-2019 } & 1 & 530,5 & 4,6 & 10,8 & 2,8 & 8,8 & 3,5 & 2,1 & 0,8 & 1,1 \\
\hline & 4 & 659,5 & 7,3 & 2,7 & 18,3 & 4,7 & 0,9 & 9,8 & 0,0 & 2,9 \\
\hline \multicolumn{11}{|c|}{ Simulação 2} \\
\hline & & & \multicolumn{4}{|c|}{ Estoque médio } & \multicolumn{4}{|c|}{ Backorder médio } \\
\hline & & to total $(\mathrm{R} \$)$ & $\mathbf{F}$ & D & $\mathbf{A}$ & $\mathbf{V}$ & $\mathbf{F}$ & D & $\mathbf{A}$ & $\mathbf{V}$ \\
\hline \multirow{2}{*}{ LOG 2019.2} & 1 & 576,5 & 13,2 & 15,8 & 9,9 & 1,8 & 1,8 & 30,2 & 41,6 & 1,9 \\
\hline & 3 & 364,5 & 3,1 & 7,3 & 9,1 & 2,4 & 4,0 & 12,8 & 9,3 & 0,4 \\
\hline \multirow{2}{*}{ WEP-2019 } & 1 & 571,5 & 4,8 & 24,1 & 11,3 & 4,9 & 3,5 & 2,1 & 0,8 & 1,1 \\
\hline & 4 & 446,5 & 9,8 & 9,8 & 13,8 & 0,3 & 0,9 & 9,8 & 0,0 & 2,9 \\
\hline
\end{tabular}

F-Fábrica; D-Distribuidor; A-Atacadista; V-Varejista

Fonte: Dados da pesquisa (2020).

Analisando a Tabela 4 é possível perceber, assim como nos pedidos, que as equipes com menor custo total se sobressaíram em relação ao estoque e backorder médio. Mas, é importante salientar que para não haver estoque ou pedidos em atraso, as atividades logísticas deveriam estar totalmente alinhadas. 


\section{AVALIAÇÃO DO JOGO PELOS PARTICIPANTES}

No WEP-2019 estiveram presentes 16 alunos e todos foram respondentes, dos quais $87,5 \%$ destes, eram alunos do primeiro ciclo, o Bacharelado em Ciência e Tecnologia, 6,25\% correspondiam aos alunos de Licenciatura em Computação e Informática e 6,25\% ao curso de Engenharia de Produção. No semestre 2019.2, somente 10 alunos responderam, destes, 90\% eram matriculados no curso que a disciplina faz parte, e, somente $10 \%$ eram alunos do primeiro ciclo. Isso impacta no nível de conhecimento prévio sobre as temáticas envolvidas. A disciplina em que o jogo é realizado faz parte do segundo ciclo, ou seja, da ênfase em Engenharia de Produção.

Dos alunos que participaram do WEP-2019, 56,25\% já haviam experienciado jogos didáticos. No semestre 2019.2, a prevalência de $80 \%$, também foi de alunos que já tinham participado de jogos didáticos antes. A utilização de jogos didáticos é uma prática presente em outras disciplinas do curso, com isso o aluno pode desenvolver mais habilidades e facilita a explicação da dinâmica do jogo. Quanto às questões de múltipla escolha, os resultados estão apresentados na Figura 4 (a representação da escala é dada entre 1 - discordo totalmente e 7 concordo totalmente).

Figura 4 - Gráfico dos resultados da aplicação da dinâmica do Beer Game

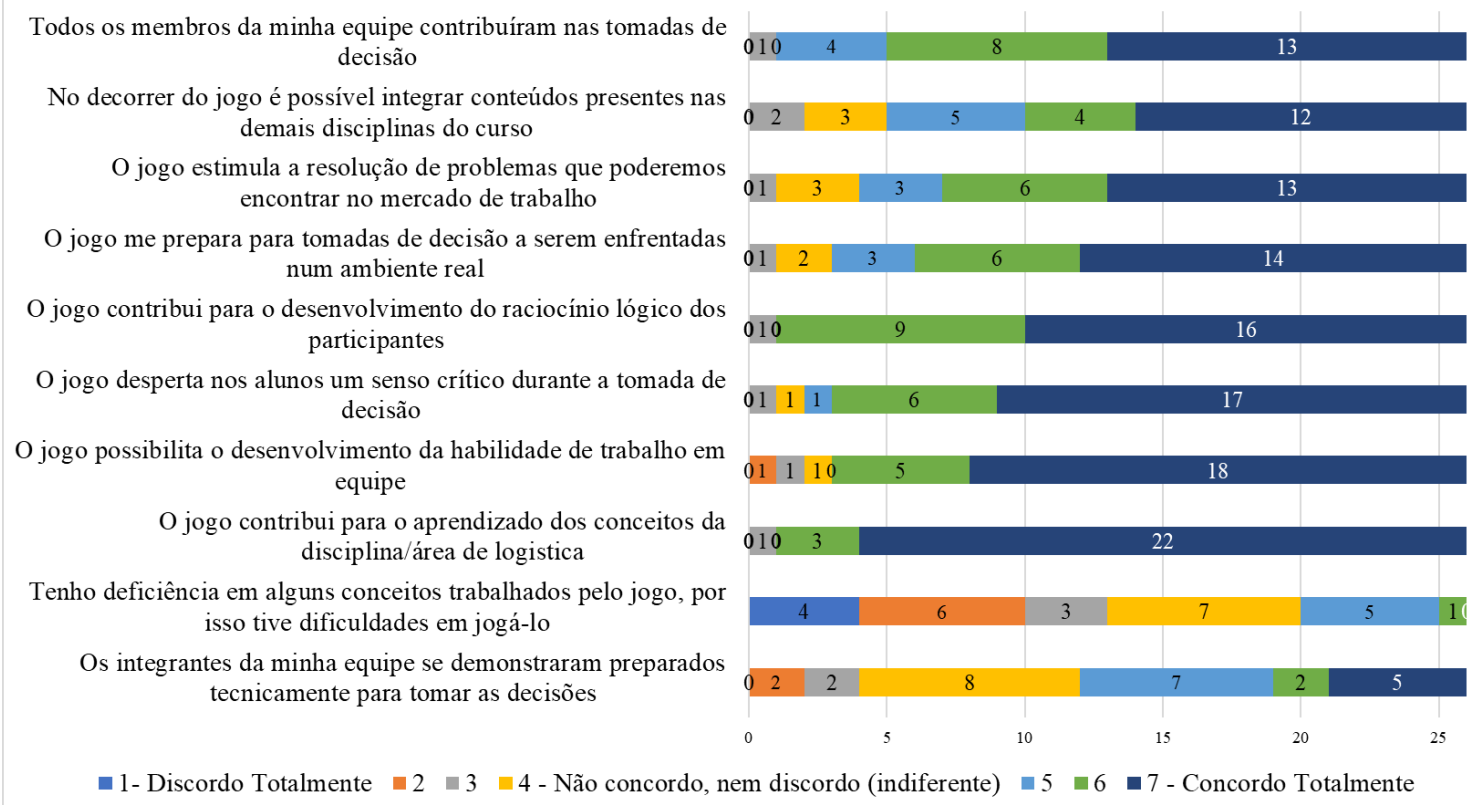

Fonte: Dados da pesquisa (2020).

A Figura 4 mostra as respostas dos 26 alunos que participaram da dinâmica durante o WEP2019 e o semestre 2019.2, deste modo, é possível analisar a percepção dos alunos quanto ao jogo e sua contribuição para o entendimento de assuntos relacionados a disciplina. Assim, é perceptível que nas perguntas sobre integração com outras disciplinas, resolução de problemas, tomada de decisão real, raciocínio lógico, senso crítico, trabalho em equipe e aprendizado de conceitos importantes, no mínimo 61,54\% dos respondentes afirmaram que concordam em nível 6 ou 7 (concordo totalmente). Com relação aos conceitos trabalhados pelo jogo, os participantes responderam o questionário citando três. Percebe-se que existem conceitos em comum entre as duas, tais como, "cadeia de suprimentos", "efeito chicote", "estratégia" e "logística". Sendo citados, com importância secundária: "planejamento", "transporte", 
"previsão da demanda". À vista disso, subtende-se que esses conceitos ficaram esclarecidos para os participantes da dinâmica. O feedback da dinâmica está exposto na Tabela 5.

Tabela 5 - Feedback dos participantes sobre a dinâmica Beer Game

\begin{tabular}{cl}
$\begin{array}{c}\text { Semestre letivo } \\
\text { de aplicação }\end{array}$ & \multicolumn{1}{c}{ Feedback dos participantes } \\
\hline & $\begin{array}{l}\text { Muito interessante trabalhar com jogos, estimula nosso lado de líder, trabalho em equipe, e } \\
\text { nas tomadas de decisões. }\end{array}$ \\
\cline { 2 - 3 } 2019.2 & $\begin{array}{l}\text { Jogo bastante criativo, no qual desperta a tomada de decisão dos participantes, mostrando } \\
\text { um pouco como funciona o mercado de trabalho nessa área. Desse modo, os participantes } \\
\text { conseguem "aprender fazendo", uma forma melhor de absorver o assunto. }\end{array}$ \\
\cline { 2 - 2 } & $\begin{array}{l}\text { O jogo é importante para o desenvolvimento do aluno, uma das principais percepções do } \\
\text { aluno é a importância da informação e perceber o seu fluxo. }\end{array}$ \\
\hline
\end{tabular}

Fonte: Dados da pesquisa (2020).

\section{CONSIDERAÇÕES FINAIS}

A aplicação do Beer Game como uma das atividades dentro da disciplina vem apresentando resultados significativos no aprendizado dos alunos, pois possibilita a visão prática de alguns conteúdos e o desenvolvimento de habilidades e atitudes relacionadas à rotina do engenheiro de produção em setores que envolvem logística e cadeia de suprimentos.

Os conceitos discutidos em sala de aula como gerenciamento de estoques, custo total da cadeia de suprimentos, efeito chicote, logística, gerenciamento de pedidos, custos de estoque e custos de transporte são visualizados na prática, por meio de gráficos e tabelas. Dessa forma, a capacidade de resolver problemas diante desta situação se torna uma das competências desenvolvidas. Além disso, o discente percebe as diferentes decisões que poderiam ser tomadas e como cada uma delas interfere de uma forma diferente no jogo/vida real.

Diante disso, é perceptível que, segundo a opinião dos participantes, o jogo estimula o desenvolvimento do aluno no tocante à tomada de decisão, trabalho em equipe, liderança, além da importância sobre a troca de informações, que recai sobre o alinhamento das operações logísticas, bem como simular situações que acontecem no mercado de trabalho.

Além disso, a docente percebe que a prática deste jogo se encaixa de forma ideal ao final da disciplina, como uma forma de consolidar o que foi aprendido, de forma dinâmica e centrada no aluno. E quando aplicado em situações fora do contexto da disciplina, é um meio de expor ao aluno o impacto da tomada de decisão não apenas em sua empresa, mas em toda cadeia, sendo uma forma de atraí-lo a cursar posteriormente a disciplina e reforçar a importância da troca de informações entre os membros da cadeia de suprimentos.

\section{REFERÊNCIAS}

BUTZKE, M. A.; ALBERTON, A. Estilos de aprendizagem e jogos de empresa: a percepção discente sobre estratégia de ensino e ambiente de aprendizagem. REGE-Revista de Gestão, v. 24, n. 1, p. 72-84, 2017.

FONSECA, S. M.; MATTAR NETO, J. A. Metodologias ativas aplicada à educação a distância: revisão de literatura. Revista Educação a Distância e Práticas Educativas Comunicacionais e interculturais (EDaPECI). v. 17, n. 2. Mai/ago 2017. 
MITRE, S. M. I. et. al. Metodologias ativas de ensino-aprendizagem na formação profissional em saúde: debates atuais. Ciências e Saúde Coletiva. v. 13, 2008.

PINTO, A. S. S.; BUENO, M. R. P.; SILVA, M. A. F. A.; SELLMANN, M. Z.; KOEHLER, S. M. F. Inovação didática- projeto de reflexão e aplicação de metodologias ativas de aprendizagem no ensino superior: uma experiência com "Peer Instruction". Revista Janus. Ano VI, n. 15. Jan/jun 2012.

PONTAROLO, M. C. C. et al. JOGO DIDÁTICO-APLICANDO CONCEITOS DE PRODUÇÃO E O TRABALHO EM EQUIPE. 2019. In: XIX Colóquio Internacional de Gestão Universitária. Florianópolis. Anais. 2019a.

PONTAROLO, M. C. C. et al. DESENVOLVIMENTO E UTILIZAÇÃO DE JOGOS EMPRESARIAIS EM DISCIPLINAS DO CURSO DE ENGENHARIA DE PRODUÇÃO. 2019. In: XLVII Congresso Brasileiro de Ensino em Engenharia. Fortaleza. Anais. 2019b.

RIBEIRO, A. R.; RIBEIRO, B. A.; LEÃO JUNIOR, C. M. Capacitação continuada: o jogo como recurso pedagógico importante no processo ensino aprendizagem. In: Congresso Internacional de Educação no Brasil. Porto Seguro: Anais. 2012.

SILVA, J. R. Aplicação da lógica MRP/ DRP no Beer Game através do desenvolvimento de uma planilha como ferramenta de capacitação. 2013. Projeto de graduação- Curso de engenharia de produção, Universidade Federal do Rio de Janeiro (UFRJ), Rio de Janeiro, 2013.

STROZZI, F.; BOSCH, J.; ZALDÍVAR, J. M. Beer game order policy optimization under changing customer demand. Elsevier, [s. l.], 2006.

\section{BUSINESS GAME FROM THE PERSPECTIVE OF TEACHING- LEARNING: APPLICATION OF THE BEER GAME}

Abstract: Business games are used in teaching with the aim of simulating a business environment, being able to relate the concepts of a theoretical class with a real problem in a controlled situation. In this sense, the present study aims to analyze the technical capacity in terms of decision making, group work and mastery of the students' concepts regarding supply chain management, through the application of the Beer Game as an evaluative element within a discipline and at events, such as a workshop. It was observed that this practice within the planning of the discipline is a means to consolidate, in a dynamic and student-centered way, what has been learned. And in events, it allows exposing the student to the impact of decision making not only in his company, but in the entire chain. For more than $61.54 \%$ of the survey participants, the game fully or almost totally reflects a real decision-making situation, with problem solving, logical reasoning, critical thinking, teamwork, integrates with other disciplines and allows learning important concepts such as "supply chain", "bullwhip effect" and "logistics".

Keywords: Business games. Beer Game. Logistics. Supply chain. 